\title{
Sezaryen Sonrası Vajinal Doğum İsteği Bulunan Gebelerde Doğum Şekli ile Doğum Korkusu Arasındaki İlişkinin İncelenmesi
}

\section{Investigation of Relationship Between Mode of Delivery and Fear of Childbirth in Candidates of Vaginal Birth after Cesarean Section}

\author{
${ }^{1}$ Ahmet ESER, ${ }^{2}$ Tuğba YILMAZ ESENCAN, ${ }^{3}$ Semra KESKIN \\ ${ }^{1}$ Zeynep Kamil Kadın ve Çocuk Hastalıkları Eğitim ve Araştırma Hastanesi, İstanbul, Türkiye \\ ${ }^{2}$ Üsküdar Üniversitesi Sağlık Bilimleri Fakültesi Ebelik Bölümü, İstanbul, Türkiye \\ ${ }^{3}$ Türkiye Sağlık Enstitüleri Başkanlığı, İstanbul, Türkiye \\ Ahmet Eser: https://orcid.org/0000-0001-6699-1810 \\ Tuğba Y1lmaz Esencan: https://orcid.org/0000-0002-8748-0793 \\ Semra Keskin: https://orcid.org/ 0000-0002-8403-1327
}

\section{ÖZ}

Amaç: Araştırma, sezaryen sonrası vajinal doğum isteyen miyad gebelerde doğum şekli ile doğum korkusu arasındaki ilişkiyi incelemek amacıyla yapılmıştır.

Materyal ve Metot: Araştırma, 37-41. gebelik haftasında sağlıklı doğum yapan 66 gebe ile gerçekleştirilmiştir. Veri toplama aşamasında kişisel bilgi formu, sezaryen sonrası vajinal doğum risk değerlendirme formu ve Wijma Doğum Beklentisi/Deneyimi Ölçeği B versiyonu kullanılmıştır. Araştırmada elde edilen verilerin değerlendirilmesinde; ortanca, çeyerekler arası aralık ve Mann-Whitney U testi uygulanmıştır.

Bulgular: Araştırmaya katılanların \%54,5'i 30 yaş ve üzerinde olup \%53'ü sezaryen sonrası vajinal doğum yapmıştır. Araştırmaya katılanlar arasında sezaryen sonrası vajinal doğum ve sezaryen ile doğum gerçekleştirenlerin WDEQ-B puan skorları karşılaştırılmış doğum şekli ile doğum korkusu arasında istatistiksel olarak anlamlı bir ilişki bulunmamıştır (U:478,5 p: 0,41).

Sonuç: Sezaryen sonrası vajinal ile doğum isteği bulunan hastalarda doğum korkusu ile doğum şekli arasında anlamlı bir ilişki olmadığı saptanmıştır. Konu ile ilgili çalışma sayılarının yetersiz olması nedeniyle yeni çalışmaların yapılması önerilmektedir.

Anahtar Kelimeler: Doğum korkusu, gebelik, sezaryen sonrası vajinal doğum

\begin{abstract}
Objective: This study investigates the relationship between fear of childbirth and mode of delivery in candidates of vaginal birth after cesarean section.

Materials and Methods: 66 term pregnants were included in the study. Participants completed the personal information form, post cesarean section vaginal birth risk evaluation form and the Wijma Delivery Expectancy/ Experience Questionnaire (W-DEQ) version B. MannWhitney $U$ test was used to analyse the differences between groups.

Results: Women over age 30 was 54.5 percent of the total population. 53 percent of women performed vaginal delivery after cesarean section. There were no significant differences between scores of WDEQ-B. (U.478,5 p:0,41). Conclusion: Fear of chidbirth and mode of delivery might not be associated in candidates of vaginal birth after cesarean section.There will be needed further studies to investigate the relationship between fear of childbirth and mode of delivery in women candidates of vaginal birth after cesarean section.
\end{abstract}

Keywords: Fear of childbirth, pregnancy, vaginal birth after cesarean section
Sorumlu Yazar / Corresponding Author:

Tuğba Yılmaz Esencan

Adres: Üsküdar Üniversitesi Sağlık Bilimleri Fakültesi Ebelik

Bölümü, İstanbul, Türkiye

Tel: +90 5057084946

E-mail: tugba.yilmazesencan@uskudar.edu.tr
Yayın Bilgisi / Article Info:

Gönderi Tarihi/ Received: 07/04/2021

Kabul Tarihi/ Accepted: 06/07/2021

Online Yayın Tarihi/ Published: 05/09/2021

Atıf / Cited: Eser A ve ark. Sezaryen Sonrası Vajinal Doğum İsteği Bulunan Gebelerde Doğum Şekli ile Doğum Korkusu Arasındaki İlişkinin İncelenmesi . Online Türk Sağlık Bilimleri Dergisi 2021;6(3):419-425. doi: 10.26453/otjhs.910376

\section{GİRIŞ}

Gebelik, doğum ve doğum sonu dönem birçok kad1nın yaşam döngüsü içerisinde deneyimlediği eşsiz bir süreç olmasının yanında beraberinde korku ve stresi de barındırmaktadır. ${ }^{1,2}$ Gebeliğe uyum sürecinde yaşanan duygusal dalgalanmalar sırasında gelişen tutum bir kültürden diğerine farklılık gösterdiği gibi, gebenin ve ailenin kültürel özelliklerinden, epigenetik aktarımlardan, doğum ortamından, sağlık profesyonellerinin tutumlarından ve kadının sağlık bakım gereksinimlerinden etkilenmektedir. ${ }^{3-5}$ 


\section{MATERYAL VE METOT}

Araştırmanın etik izinleri, araştırmanın uygulanacağ hastanenin klinik araştırmalar etik kurulundan alınmıştır (Tarih: 23.03.2018, karar no: 46). Gönüllülük esas alınarak araştırmaya katılmayı kabul eden gebeler, araştırmanın amacı ve uygulanması hakkında bilgilendirilmiş, sözlü ve yazılı izinleri alınmıştır. Kesitsel ve tanımlayıcı olarak yürütülen bu araştırma, İstanbul ilinin Anadolu yakasında bulunan bir eğitim ve araştırma hastanesinde Kasım 2018-Mayıs 2019 tarihleri arasında gerçekleştirilmiştir. Araştırmanın evrenini belirlenen tarihler içerisinde gebe acil polikliniğine doğum amaciyla başvuran, kontrolleri sırasında sezaryen sonrası vajinal doğum isteği bulunan ve sezaryen sonrası vajinal doğum için yapılan risk değerlendirmesinin ardından herhangi bir riski bulunmayan 66 gebe oluşturmuştur. Araştırmanın örneklemi evrenin tamamını oluşturmaktadır. Gönüllülerin araştırmaya dahil edilme kriterleri;

- Araştırmanın yapıldığ 1 hastanenin doğum acil polikliniğine başvurmuş olmak;

- Miadında gebe olmak (37. Gebelik haftasını tamamlamış olmak),

- Daha önce bir kez sezaryen ile doğum yapmış olmak,

- Sezaryen sonrası vajinal doğum yapma talebinde bulunmak,

- SSVD için risk değerlenmesinin ardından uygun kriterleri taşıyor olmak,

- SSVD uygulamasının taşıdığı riskleri kabul etmek,

- Araştırmaya katılmaya gönüllü olmak ve

- Çalışma anketlerini tam doldurmak şeklinde belirlenmiştir.

Veri Toplama Araçları ve Verilerin Toplanması: Araştırma verileri, araştırmacılar tarafından literatür $^{13,16,17,21-23}$ taraması sonucu geliştirilen bilgi formu, SSVD risk değerlendirme formu ve WIJMA doğum beklentisi/deneyimi ölçeği versiyon B (WDEQ-B) ile yüz yüze görüşme yöntemi ile toplanmıştır. Verilerin toplanması aşamasında formların tam doldurulmuş olması kriter olarak alınmıştır.

Bilgi Formu: Toplam 8 sorudan oluşmaktadır. Soru dağılımı; Sosyo-demografik bilgileri içeren 5, gebelikle ilgili 3 sorudan oluşmaktadır.

Sezaryen Sonrası Vajinal Doğum Risk Değerlendirme Formu: Gebenin tekrarlayan elektif sezaryen doğum isteminin olması, önceki sezaryen operasyonunda alt segment transves dişı uterus kesisi olması, önceki sezaryen operasyonunun uterin kesisinin bili- nememesi, iki veya daha fazla alt segment transvers uterus kesisi olan sezaryen operasyonu geçirmiş olma, geçirilmiş uterin rüptür hikâyesi, geçirilmiş histerektomi veya uterin kaviteye girilmiş myomektomi öyküsü, vajinal doğuma engel maternal ve fetal diğer durumların belirlendiği 12 sorudan oluşmaktadır. Riski belirlenen 28 vaka araştırma dışında bırakılmıştır. Tüm gebelere sezaryen sonrası vajinal doğuma ait risklerle ilgili bilgilendirilme yapılmıştır. Sezaryen sonrası vajinal doğum talebinde bulunan tüm gebelere ve eşlerine doğum öncesi SSVD hakkında bilgilendirme eğitimi verilmiştir.

WIJMA Doğum Beklentisi/Deneyimi Ölçeği Versiyon $B$ (WDEQ-B): 32 sorudan oluşan ölçek Wijma ve arkadaşları (1998) tarafından geliştirilmiştir. Doğum sonrasında postpartum dönemde uygulanan Wijma Doğum Beklentisi/ Deneyimi Ölçeği B (WDEQ B) doğum eyleminin ardından ortalama 4.saatte uygulanmıştır. Ölçekten alınan toplam puan 0 ile 165 arasında değişmektedir. Puan arttıkça kadınların yaşadığı doğum korkusu artmaktadır. WDEQ-B doğum sonrasında; doğum korkusu, duygu ve düşünceler hakkında bilgi verir. Körükcü, Bulut ve Kukulu tarafindan 2014 yılında Türkçeye uyarlanarak, geçerlik ve güvenilirliği yapılan ölçeğin 6 alt grubu; doğum ağrısı ile endişe, pozitif tutum yokluğu, yalnızlık, pozitif duygularda eksiklik, doğumla ilgili endişeler ve bebekle ilgili endişeler hakkında bilgi verir. Türkçe versiyonda iç tutarlılık değeri 0,88 (yüksek derecede güvenilir) olarak bulunmuştur. $^{24,25}$

Araştırmanın Soruları: Araştırma şu sorulara yanit aramaktadir;

1. Doğum korkusu ile SSVD arasında bir ilişki var midir?

2. Doğum şekli, sosyo-demografik ve obstetrik veriler ile doğum korkusu arasında bir ilişki var mıdir?

Verilerin Değerlendirilmesi: Verilerin analizinde SPSS versiyon 22 kullanıldı. Çalışma verileri değerlendirilirken tanımlayıcı istatistiksel metotların (medyan, oran, frekans) yanı sıra normal dağılım göstermeyen parametrelerin iki grup karşılaştırmalarında Mann Whitney U test kullanıldı. Parametreler arası ilişkilerin değerlendirilmesinde de Spearman's Korelasyon analizi kullanılmıştır. Sonuçlar \%95'lik güven aralığında, anlamlılık $\mathrm{p}<0,05$ düzeyinde değerlendirilmiştir.

\section{BULGULAR}

Araştırmaya 66 gebe katılmıştır. Gebelerin yarısın- 
dan fazlasının doğumu sezaryen sonrası vajinal doğum (\%53) ile gerçekleşmiştir. Travay takibi sırasında gebe ve fetus yakından izlenmiştir. En az 30 dakikada bir 10 dakikalık kontraksiyonlar takip edilmiştir. Gebelerin ANTA bulguları her saat başı değerlendirilmiştir. Fetal monitörizasyon ile kontraksiyonlar ve fetal kalp atım paterni sürekli olarak izlenmiştir. Doğum eyleminin ilerleyişi, servikal dilatasyon ve efesman bulguları yakından takip edilerek partograf aracılığı ile kayıt altına alınmıştır. Aktif eyleme giren gebelerin servikal dilatasyonunun 1 $\mathrm{cm} /$ saat hızda ilerlemesi kriter olarak alınmıştır. $\mathrm{Bu}$ takip kriterleri göz önüne alınarak gebelerin \% 46,9'unun doğum şekli sezaryen ile sonuçlanmıştır (Tablo 1).

Gebelerin çoğunluğunun yaş grubu 30 yaş ve üzerinde olup $(\% 54,5)$ sezaryen sonrası vajinal doğum gerçekleştiren gebelerin \%57,1'i 30 yaş üzerindedir. Eğitim durumuna bakıldığında SSVD gerçekleştiren gebelerin \%34,3'ü lise mezunu iken sezaryen ile

Tablo 1. Katılımcıların doğum şekline göre sosyo-demografik-obstetrik verileri.

\begin{tabular}{|c|c|c|c|c|c|c|c|}
\hline \multirow{2}{*}{\multicolumn{2}{|c|}{ Veriler }} & \multicolumn{2}{|c|}{$\begin{array}{c}\text { Sezaryen Sonrası Vajinal } \\
\operatorname{doğum}(n=35)\end{array}$} & \multicolumn{2}{|c|}{$\begin{array}{l}\text { Sezaryen do- } \\
\text { gum(n=31) }\end{array}$} & \multicolumn{2}{|c|}{$\begin{array}{c}\text { Total } \\
(n=66)\end{array}$} \\
\hline & & $\mathbf{n}$ & $\%$ & n & $\%$ & $\mathbf{n}$ & $\%$ \\
\hline \multirow[t]{2}{*}{ Yaş } & $30 \geq$ & 20 & 57,1 & 16 & 51,6 & 36 & 54,5 \\
\hline & $30<$ & 15 & 42,9 & 15 & 48,4 & 30 & 45,5 \\
\hline \multirow[t]{5}{*}{ Eğitim } & Okuryazar değil & 1 & 2,9 & 3 & 9,7 & 4 & $\% 6,1$ \\
\hline & Ilkokul & 10 & 28,6 & 10 & 32,3 & 20 & 30,3 \\
\hline & Ortaokul & 6 & 17,1 & 5 & 16,1 & 11 & 16,7 \\
\hline & Lise & 12 & 34,3 & 9 & 29 & 21 & 31,8 \\
\hline & Lisans & 6 & 17,1 & 4 & 12,9 & 10 & 15,2 \\
\hline \multirow{3}{*}{$\begin{array}{l}\text { Aylık Ortalama } \\
\text { Gelir düzeyi }\end{array}$} & $3000 \mathrm{TL} \geq$ & 10 & 28,6 & 12 & 38,7 & 22 & 33,3 \\
\hline & $3000-5000 \mathrm{TL}$ & 22 & 62,9 & 16 & 51,6 & 38 & 57,6 \\
\hline & $5000 \mathrm{TL} \leq$ & 3 & 8,6 & 3 & 9,7 & 6 & 9,1 \\
\hline \multirow[t]{2}{*}{ Gravida } & $3 \geq$ & 27 & 77,1 & 18 & 58,1 & 45 & 68,2 \\
\hline & $3<$ & 8 & 22,9 & 13 & 41,9 & 21 & 31,8 \\
\hline \multirow[t]{2}{*}{ Parite } & $2 \geq$ & 22 & 62,9 & 18 & 58,1 & 40 & 60,6 \\
\hline & $2<$ & 13 & 37,1 & 13 & 41,9 & 26 & 39,4 \\
\hline
\end{tabular}

doğum yapanların\%32,3’ü ilkokul mezunudur. Katılımcıların \%68,2'sinin gravidası 3 ve üzerinde iken paritesi 2 ve üzerinde olanlar \%60,6'sını oluşturmaktadır. Çalışmaya katılan gebelerden SSVD yapanların çoğunun $(\% 77,1) 3$ ve üzerinde gebelik sayısının olduğu, 2 ve üzerinde doğum yapmış olup bir kez sezaryen olmuş gebelerin \%62,9'unun doğumu SSVD ile gerçekleşmiş olduğu görülmektedir (Tablo 1).

Araştırmaya katılanlar arasında sezaryen sonrası vajinal doğum ve sezaryen ile doğum gerçekleştirenlerin WIJMA Doğum Beklentisi/Deneyimi Ölçeği Versiyon B -WDEQ-B puan skorları karşılaştırılmış olup doğum şekli ile doğum korkusu arasında istatistiksel olarak anlamlı bir ilişki bulunmamıştır (U:478,5 p: 0,41). Sezaryen sonrası vajinal doğum yapmış olan katılımcılar ile sezaryen olan katılımcıların ölçek puan ortalamaları birbirlerine yakın olup düşük düzeyde doğum korkusu yaşadıkları görülmüştür (Tablo 2).
Tablo 2. WDEQ-B doğum korkusu toplam skor puanı ile doğum şeklinin karşılaştırılması.

\begin{tabular}{|c|c|c|c|c|}
\hline & $\begin{array}{c}\text { Mean } \\
\text { Rank }\end{array}$ & $\begin{array}{c}\text { Sum of } \\
\text { Ranks }\end{array}$ & $\mathbf{U}^{*}$ & $\mathbf{p}$ \\
\hline $\begin{array}{c}\text { Sezaryen } \\
\begin{array}{c}\text { Sonrası Va- } \\
\text { jinal doğum } \\
(\mathbf{n}=\mathbf{3 5})\end{array}\end{array}$ & 31,67 & 1108,5 & 478, & 0,41 \\
\hline $\begin{array}{c}\text { Sezaryen } \\
\text { doğum } \\
(\mathbf{n = 3 1})\end{array}$ & 35,56 & 1102,5 & 5 & \\
\hline
\end{tabular}

*: Mann Whitney U

WIJMA Doğum Beklentisi/Deneyimi Versiyon B ölçeği 6 alt grup altında incelenmekte olup çalışmamızda da doğum ağrısı ile endişe duyma, pozitif tutum yokluğu, yalnızlık, pozitif duygularda eksiklik, doğumla ilgili endişeler ve bebekle ilgili endişeler alt başlıklarında incelenmiş ve alt gruplardan alınan puan ortalamaları ile doğum şekli arasında istatistiksel olarak anlamlı bir ilişki bulunmamıştır 
Tablo 3. WDEQ-B alt gruplarının doğum şekli ile karşılaştırılması.

\begin{tabular}{|c|c|c|c|c|c|c|}
\hline & \multicolumn{2}{|c|}{ Vajinal Doğum(n=35) } & \multicolumn{2}{c|}{ Sezaryen Doğum(n=31) } & \multirow{2}{*}{$\mathbf{U}^{*}$} & p \\
\cline { 2 - 6 } & Mean Rank & Sum of Ranks & Mean Rank & Sum of Ranks & & \multirow{2}{*}{0,23} \\
\hline $\begin{array}{c}\text { Doğum Ağrısı } \\
\text { Endişesi }\end{array}$ & 30,86 & 1080 & 36,48 & 1131 & 450 & 0,23 \\
\hline $\begin{array}{c}\text { Pozitif tutum } \\
\text { yokluğu }\end{array}$ & 35,64 & 1247,5 & 31,08 & 963,5 & 467,5 & 0,33 \\
\hline Yalnızlık & 32,33 & 1131,5 & 34,82 & 1079,5 & 501,5 & 0,59 \\
\hline $\begin{array}{c}\text { Pozitif duygu- } \\
\text { larda eksiklik }\end{array}$ & 32,09 & 1123 & 35,1 & 1088 & 493 & 0,52 \\
\hline $\begin{array}{c}\text { Doğumla ilgili } \\
\text { endişe }\end{array}$ & 32,53 & 1138,5 & 34,6 & 1072,5 & 508,5 & 0,65 \\
\hline $\begin{array}{c}\text { Bebekle ilgili } \\
\text { endișe }\end{array}$ & 32,39 & 1133,5 & 34,76 & 1077,5 & 503,5 & 0,6 \\
\hline
\end{tabular}

*: Mann Whitney U

Tablo 4. Doğum şekli, demografik ve obstetrik faktörler ile WDEQ-B ölçeği puanları arasındaki korelasyonu.

\begin{tabular}{|l|c|c|}
\hline \multirow{2}{*}{ Korelasyon } & \multicolumn{2}{c|}{ WDEQ-B } \\
\cline { 2 - 3 } & r & p \\
\hline Doğum şekli & 0.1 & 0,41 \\
\hline Yaş & 0,15 & 0,21 \\
\hline Gravida & $-0,03$ & 0,76 \\
\hline Parite & $-0,1$ & 0,39 \\
\hline Eğitim düzeyi & 0,02 & 0,88 \\
\hline Aylık ortalama gelir & $-0,07$ & 0,56 \\
\hline
\end{tabular}

( $\mathrm{p} \geq 0,05)$.

Ölçek alt başlıkları içerisinde doğum şekli ile alınan puanlar birbirine yakın olup SSVD ile doğum yapanların sezaryen doğum ile doğum yapanlara göre daha az doğum ağrısı konusunda endişe yaşamış olup yine doğum ve bebekle ile ilgili endişe puanlarının sezaryen ile doğum yapanlara oranla daha düşük olduğu görülmüştür (Tablo 3).

Doğum şekli, sosyo-demografik ve obstetrik veriler ile doğum korkusu arasında bir ilişki olup olmadığı incelendiğinde; WIJMA Doğum Beklentisi/ Deneyimi Ölçeği Versiyon B ölçeği puan ortalamalarının doğum şekli, yaş, gravida, parite, eğitim düzeyi ve aylık gelir düzeyi verileri yönünden istatistiki olarak etkisi olmadığı tespit edilmiştir (Tablo 4).

\section{TARTIŞMA VE SONUÇ}

Anne ve bebek sağlığı açısından uluslararası bir gündem olan sezaryen ile doğum oranlarının ülkemizde de oldukça yüksek olması ciddi önlemlerin alınması gereksinimini karşımıza çıkarmaktadır. Özellikle daha önce geçirilmiş bir sezaryen öyküsünün olmasının ardından gerçekleşecek olan doğumlarında yine sezaryen ile gerçekleşmesi zorunluluğu- na karşın uygun özellikleri taşıyan vakalara SSVD uygulaması alınabilecek bu önlemlerin başında gelmektedir. ${ }^{16,23,26}$ Yapılan çalışmalarda da sezaryen ile doğum yapan kadınlarda vajinal doğum yapanlara göre postpartum kardiyak arrest riski, yara hematomu, enfeksiyon, anestezi komplikasyonları, hastanede kalış süresi, venöz tromboembolizm, yapışıklıklar, mesane ve bağırsak yaralanmaları, plasenta previa ve histerektomiyi gerektiren kanama riskinin yüksek olduğu belirlenmiştir. ${ }^{15-17,22} \mathrm{Bu}$ sonuçlar birçok araştırma ile de doğrulanmıştır. ${ }^{15,16}$ Günümüzde bilimin sunduğu veriler doğrultusunda özellikle sezaryen sonrası normal doğum indüksiyon denemesi ve SSVD ile artan sezaryen doğum oranlarını azaltma çabaları yaygınlaşmıştır. ${ }^{15,17}$

SSVD ile ilgili yapılan çalışmalar ışığında vaka seçiminde dikkatli olunması, yakın fetal ve maternal takip imkanı olan merkezlerde doğumun gerçekleşmesi, ilave bir uterin cerrahi bir operasyon geçirmemiş ve pelvisi uygun olan gebeler ile uygulanması önerilmiştir. ${ }^{16}$ Sezaryen ile doğum hayat kurtarıcı bir cerrahi operasyon olmasının yanında uygulamanın içerisinde barındırdığı riskleri de göz önünde bulundurmak gerekmektedir. Özellikle daha sonraki gebe- 
liklerde ektopik gebelik, plasenta implantasyon anomalileri, febril ve tromboembolik riskler ile ciddi komplikasyonlara da neden olabilmektedir. Tüm bu maternal ve neonatal riskler düşünüldüğünde gerekmedikçe uygulanmaması gerekmektedir. Ayrıca daha önce sezaryenle doğum yapmış gebelerin vajinal doğum istekleri ve uygunluk durumları da değerlendirilmelidir. Geçmişten günümüze yapılan çalışmalar incelendiğinde SSVD'yi tercih eden gebelerin çoğunlukla genç yaş grubunda olan gebelerden oluştuğu görülmüştür. Yaş ortalamasının 30'un altında olmasının SSVD başarı oranını arttırdığ1 düşünülmüştür. ${ }^{20,23-26}$ Çalışmamızda ise sezaryen ile doğum yapmış olup SSVD talebi olan gebelerin \%54,5'inin 30 yaşın üzerinde olduğu ve SSVD ile doğum yapanlara baktığımızda \%57,1'inin yine 30 yaşının üzerinde olduğu görülmektedir. Günümüzde gebelik yaş ortalamasının artmış olması çalışma verilerimize de bu yönde yansımıştır.

Sezaryen sonrası vajinal doğum başarısı ile ilişkili faktörlerin incelendiği bir kohort çalışmasında 143.970 kadından 75.086'sının $(\% 52,2)$ ikinci doğumları için SSVD girişiminde bulunduğu ve 47.602 kadının $(\% 63,4)$ başarılı bir şekilde vajinal doğum yaptığı görülmüştür. ${ }^{16}$ Araştırmamızda da gebelerin $\% 60,6$ 'sının paritesinin iki ve üzerinde olduğu, \% 53'ünde sezaryen sonrası vajinal doğumun gerçekleştiği bulunmuştur. Sezaryen sonrası vajinal doğum için uygun kriterleri taşıyan her gebeye vajinal doğum şansının tanınması gerektiği ve bunun sonucunda başarıya ulaşmanın ise \%50'nin üzerinde olduğu çalışmamızda da ortaya konulmuştur.

Gebelerde doğum ile ilgili bilgi düzeyi ile doğum ve doğum korkusunun ilişkisinin incelendiği bir araştırmada doğumla ilgili olarak en çok yanlış bilinen bilginin ise \%59,9 ile "Sezaryenle doğumdan sonra tekrar normal doğum yapılmaz" bilgi sorusu olduğu bildirilmiştir. ${ }^{27}$ Genel algı olarak sezaryen sonrası gerçekleşecek olan doğumun yeniden sezaryen ile gerçekleşmesi gerektiği bilgisi yaygın olarak karşılaŞılan yanlış bir bilgidir. Çalışmamız süresince SSVD talebinde bulunan 94 gebe ile yapılan risk değerlendirmesinin ardından 66 gebenin SSVD için uygun kriterleri taşıdığı görülmüştür. Gebe sayımızın az olması gebelerin SSVD konusunda bilgi düzeylerinin yetersiz olmasından kaynaklı olduğunu düşündürmüştür.

Literatürü incelediğimizde obstetrik problemlerin en önemli kaynaklarından biri olarak doğum korkusu karşımıza çıkmaktadır. Doğumda her on kadından birinin doğum korkusu kaynaklı distosi yaşadıkları görülmektedir. Doğum korkusunu irdeleyen çalış- malarda nullipar gebelerin doğum korkusunun multiparlardan daha yüksek olduğu belirtilmektedir. $^{23,27,28}$ Yapılan çalışmalarda eğitim seviyesi ile özyeterlilik arttıkça doğum korkusunun azaldığı ve anne ve bebek bağlanmasının da güçlendiği belirtilmektedir. ${ }^{27,28}$ Bülbül ve ark. 2016 yılında yapmış oldukları çalışmada ise doğum korkusunun gebelerin doğum tercihleri üzerinde etkili olduğu ve sezaryen ile doğum yapma tercihinde bulunan gebelerin \% 28.6'sının doğum korkusu nedeniyle bu tercihte bulundukları belirtilmiştir. ${ }^{29}$ Çalışmamızda sezaryen sonrası vajinal doğum yapmış olan kadınlar ile sezaryen olanların doğum korkusu yönünden birbirlerine yakın düzeyde olduğu, yaş, gravida, parite, eğitim düzeyi ve aylık gelir düzeyi verileri yönünden aralarında anlamlı bir fark olmadığı, ve düşük düzeyde doğum korkusu yaşadıkları görülmüştür. $\mathrm{Bu}$ durum gebelerin bilgilendirilmiş olması ve eğitim verilmiş olması ile ilişkilendirilmiştir. Yapılan diğer çalışmalarda da gebelikte verilen doğum öncesi eğitimlerin doğumla ilgili yanlış bilinenlerin düzeltilmesinde ve doğum korkusunun azaltılmasında etkili olduğu saptanmıştır. ${ }^{22,23,26-29}$

Çalışmamız sonucunda sezaryen sonrası vajinal doğum yapma talebinde bulunan gebelerin kadın doğum hekimleri tarafindan yapılan doğru bir risk değerlendirmesi ardından verilen eğitim, ebe desteği ve doğum sırasında sürekli ebelik bakımı ile vajinal doğum yapabildikleri görülmektedir. Araştırmamızda $\% 53$ oranında sezaryen sonrası başarılı bir şekilde vajinal doğum gerçekleşmiş olup herhangi bir komplikasyon yaşanmamıştır. $\mathrm{Bu}$ sürecin takibinin bir ekip işi olduğu unutulmamalıdır. Doğru vaka seçiminde SSVD konusunda destekleyici bir kadın doğum hekiminin varlığı oldukça etkili olmaktadır. Gebelerin doğuma hazırlık sınıflarında verilen eğitimler ile bilgilendirilerek bir kez sezaryen olmanın hep sezaryen olmadığı bilgisi ile doğuma hazırlanmalarının sezaryen doğum oranlarının azalmasında etkili olacağı düşünülmektedir. Doğuma hazırlık sınıflarında verilecek bu eğitimler ile hem gebeler hem de babalar doğumu daha bilinçli karşılayacaklardır. Ebelerin doğuma hazırlık sınıflarında gebelere gereksinimleri yönünde eğitim vermeleri, özellikli eğitim gereksinimi olan gebeleri belirlemeleri ve SSVD konusunda doğru bilgi, bakım ve eğitimi vermeleri önerilmektedir.

Etik Komite Onayı: Araştırmanın uygulandığı hastanenin klinik araştırmalar etik kurulundan etik izin alınmıştır (Tarih: 23.03.2018, karar no:46).

Çıkar Çatışması: Yazarlar çıkar çatışması bildir- 
memişlerdir.

Yazar Katkıları: Fikir -AE; Denetleme -AE, TYE; Malzemeler -AE, TYE, SK; Veri toplanması ve işlemesi - AE, SK; Analiz ve yorum -AE; Yazıyı yazan -TYE.

Hakem değerlendirmesi: Dış bağımsız.

Teşekkür: Çalışmaya katılan tüm gebelere teşekkür ederiz.

\section{KAYNAKLAR}

1. Güdücü N, Kayan BÖ, İşçi H, Yiğiter BA, Dünder I. Sezaryenle ve normal doğum yapan kadınlarda postpartum posttravmatik stres bozukluğu. JOPP Derg. 2013;5(3):114-117. doi:10.5222/JOPP.2013.114

2. Coşar F, Demirci N. The effect of childbirth education classes based on the philosophy of lamaze on the perception and orientation to labour process. S.D.U. Journal of Health Sciences. 2012;3 (1):18-30.

3. Carter SK, Guittar SG. Emotion work among pregnant and birthing women. Midwifery. 2014;30:1021-1028. doi: 10.1016/ j.midw.2014.05.003

4. Daş Z. Gebeliğin psiko-sosyal ve kültürel boyutu. Taşkın L, ed. Doğum ve Kadın Sağlı̆̆ 1 Hemşireliği. Ankara: Sistem Offset Printing; 2016:254-265.

5. İşbir GG, İnci F, Önal H, Yıldız PD. The effects of antenatal education on fear of childbirth, maternal self-efficacy and post-traumatic stress disorder (PTSD) symptoms following childbirth: an experimental study. Appl Nurs Res. 2016;32:227 -232. doi:10.1016/j.apnr.2016.07.013

6. Aktaş S. Multigravidas' perceptions of traumatic childbirth: its relation to some factors, the effect of previous type of birth and experience. Medicine Science International Medical Journal. 2018;7(1):203-209. doi:10.5455/ medscience.2017. 06.8728

7. Pınar ES, Yıldırım G, Cesur B, Éliás Z, Kayapınar NH, Şekeroğlu S. Expression of feelings by pregnant women living in two different geographic regions and their adaptation to pregnancy: Hungary and Turkey cases. Sakarya Med J. 2018;8(3):582-592. doi:10.31832/smj.421885

8. Anderson CA. The trauma of birth. health care. Women Int. 2017;38(10):999-1010. doi:10.1080/07399332.2017.1363208

9. Yalnız H, Canan F, Genç RE, Kuloğlu MA, Geçici Ö. Development of a scale of traumatic childbirth perception. Turkish Med J. 2016;8
(3):81-88.

10. İşbir GG, İnci F. Traumatic childbirth and nursing approaches. KASHED. 2014;1(1):29-40.

11. Wiklund I, Andolf E, Lilja H, Hildingsson I. Indications for cesarean section on maternal request- guidelines for counseling and treatment. Sexual \& Reproductive Healthcare. 2012;3(3):99 -106. doi:10.1016/j.srhc.2012.06.003

12.Lukasse M, Schei B, Ryding EL. Prevalence and associated factors of fear of childbirth in six european countries. Sexual \& Reproductive Healthcare. 2014;5(3):99-106. doi:10.1016/ j.srhc.2014.06.077

13. Kaplanoğlu M. Sezaryen sonrası vajinal doğum. Archives Medical Review Journal. 2014;23 (4):624-636. doi:10.17827/aktd.97420

14. Karabel PM, Demirbaş M, İnci BM. Türkiye'de ve Dünya'da değişen sezaryen sıklığı ve olası nedenleri. Sakarya Tip Dergisi. 2017;7(4):158163. doi:10.31832/smj.368600

15.Kaplanoğlu M, Bülbül M, Kaplanoğlu D, Bakacak MS. Effect of multiple repeat cesarean sections on maternal morbidity: data from southeast Turkey. Medical Science Monitor. 2015;21:1447-1453. doi:10.12659/MSM.893333

16. Knight H, Gurol Urganci I, Van Der Meulen J, ve ark. Vaginal birth after caesarean section: a cohort study investigating factors associated with its uptake and success. BJOG. 2014;121:183192. doi:10.1111/1471-0528.12508

17. Schoorel ENC, Van-Kuijk SMJ, Melman S, ve ark. Vaginal birth after a caesarean section: the development of a western european populationbased prediction model for deliveries at term. An International Journal of Obstetrics \& Gynaecology. 2014;121:194-201. doi:10.1111/14710528.12539

18. Erenel ŞA, Aksu PS. Sezaryen Sonrası vajinal doğum: neden ve hangi koşullarda? Gümüşhane Üniversitesi Sağlık Bilimleri Dergisi. 2017;6 (3):235-42.

19.Lopez E, Patkai J, El Ayoubi M, ve ark. Benefits and harms to the newborn of maternal attempt at trial of labor after prior caesarean versus elective repeat caesarean delivery. J Gynecol Obstet Biol Reprod. 2012;41:727-34. doi:10.1016/ j.jgyn.2012.09.034

20. Madi JM, Deon J, Rombaldi RL, Araujo FB, Rombaldi MC, Santos BM. Impact of vaginal delivery after a previous cesarean section on perinatal outcomes. Rev Bras Ginecol Obstet. 2013;35:516-22. doi:10.1590/s0100- 
72032013001100007

21. Karabulutlu Ö. Kadınların doğum şekli tercihlerini etkileyen faktörler. Florence Nightingale Hemşirelik Dergisi. 2012;20(3):210-218.

22. Størksen HT, Garthus Niegel S, Adams SS, Vangen S, Eberhard-Gran M. Fear of childbirth and elective caesarean section: a populationbased study. BMC Pregnancy Childbirth.2015. doi:10.1186/s12884-015-0655-4

23. Jahromi AS, Rahmanian K, Madani A. Relation of knowledge about cesarean disadvantages and delivery mode selection in women with first pregnancy; south of Iran. J Res Med Dent Sci. 2018;6(2):550-556. doi:10.5455/jrmds.20186283

24. Wijma K, Wijma B, Zar M. Psychometric aspects of the w-deq: a new questionnaire for the measurement of the fear childbirth. Journal of Psychosomatic Obstetrics \& Gynecology. 1998;19(2):84-97. doi:10.3109/01674829809048501

25.Körükcü O, Bulut O, Kukulu K. Psychometric evaluation of the wijma delivery expectancy/ experience questionnaire version B. Health Care for Women International. 2014;13:1-18. doi:10.1080/07399332.2014.943838

26. Kavak SB, Çelik Kavak E, Kurkut B, ve ark. Sezaryen sonrası vajinal yolla doğum: retrospektif değerlendirme. J Clin Obstet Gynecol. 2013;23(4):215-219.

27. Şahin S, Güler SD, İlçioğlu K, Ünsal A. Gebelerde doğum ile ilgili bilgi düzeyi ve doğum korkusunun değerlendirilmesi. Bakırköy Tıp Dergisi. 2019;15:5-14. doi:10.4274/ BTDMJB.galenos.2017.20170603015031

28. Haapio S, Kaunonen M, Arffman M, AstedtKurki P. Effects of extended childbirth education by midwives on the childbirth fear of first-time mothers: an RCT. Scand J Caring Sci. 2017;31:293-301. doi:10.1111/scs.12346

29. Bülbül T, Özen B, Çopur A, Kayacık F. Gebelerin doğum korkusu ve doğum şekline karar verme durumlarinin incelenmesi. Journal of Health Sciences. 2016;25(3):126-130. 